\title{
MIAV: AN INCLUSIVE METHOD FOR ACCESSIBILITY ASSESSMENT BY VISUALLY IMPAIRED PEOPLE
}

\author{
Gabriel de Almeida Souza Carneiro and Maria Alciléia Alves Rocha \\ IFFluminense \\ Dr. Siqueira, 273, Campos dos Goytacazes - RJ, 28030-130, Brazil
}

\begin{abstract}
Today the Internet is the most popular source of information. Therefore, web content should suit both a general audience and visually-impaired individuals. Consequently, web software products should be assessed to fulfill accessibility standards. This paper introduces an inclusive method for accessibility assessment by visually-impaired users named MIAV. The MIAV enables visually-impaired users to assess the accessibility of web software without supervision. This proposed method complies with the Web Content Accessibility Guidelines (WCAG) and the Brazilian e-Government Accessibility Model (eMAG), combining an automated approach with an approach grounded on the user experience and opinion of visually-impaired individuals. To design this method, we followed a sequence of steps. First, we carried out a pilot test to identify improvements to MIAV. Second, we had three visually-impaired students apply MIAV to assess IFFluminense's portal's, Q-Academico's and Moodle's accessibility. Finally, we ran AccessMonitor, an accessibility assessment tool advised by $\mathrm{W} 3 \mathrm{C}$, to evaluate the same web applications and obtained two indicators: average accessibility index and percentage of nonconformities by accessibility level. Results showed that none of the evaluated web pages met all the accessibility criteria. The resulting average accessibility index for Q-Academico, IFFluminense's portal and Moodle were 4.3 and 5.6 and 6.8 respectively. In addition, the visually-impaired students identified several accessibility issues. Therefore, we suggest improvements for the assessed web applications to provide a better user experience for visually-impaired students.
\end{abstract}

\section{KEYWORDS}

Accessibility, eMAG, Usability, Visual Impairmentand WCAG

\section{INTRODUCTION}

In Brazil, education provision for people with disabilities has changed dramatically over the years. In the 1980s, the Brazilian Constitution guaranteed disability people attendance, preferably, in regular education. After that, the Brazilian Education Guidelines and Framework Law (LDB) emphasized the need for specialized support services (BRASIL, 1996). Also, LDB enforces and promote, under conditions of equality, exercise of primary rights and freedoms aiming at their social inclusion and citizenship (BRASIL, 2015). The Brazilian population is estimated in 200.6 million, $6.2 \%$ of which have at least one of four disabilities (intellectual, physical, auditory or visual) wherein visual impairment (3.6\%) is the most representative (IBGE, 2013). These people may face learning issues.

The Internet provides new educational features that people with disabilities could use. In this case, assistive technologies aid the visually-impaired so that they could carry out activities independently (Sartoretto and Bersch, 2017). Web content should be available according to the accessibility recommendations, such as Brazilian eMAG (e-Government Accessibility Model) (BRASIL, 2014) and ISO/IEC 40500: 2012 (ISO/IEC, 2012) which standardized the WCAG (Web Content Accessibility Guidelines). The ISO/IEC 25010 defines accessibility as the extent to which a product or system can be used by the largest number of people regardless of their physical characteristics or capability to achieve a specified goal in a particular context of use (ISO/IEC, 2011).

IFFluminense's (a Brazilian VET school in upstate Rio) students use web applications in their academic activities, such as IFFluminense's Portal (BRASIL, 2018), Q-Academico (QUALIDATA, 2017) and Moodle (MOODLE, 2017). IFFluminense's Portal publishes news on academic activities. Students access information about their grades and attendances using Q-Academico. Teachers can make available educational content and 
assignment in Moodle. Despite the current Laws, guidelines and NAPNEE's (the Support Center for Students with Special Educational Needs) assistance for IFFluminense's students, blind students face accessibility issues when using those applications. Depending on the activity, accessibility failure can impact these students' learning and academic achievement.

The main objective of this work is to develop a method that allows visually-impaired individuals to assess web applications' accessibility, named MIAV (Inclusive Method for Accessibility Assessment by Visually-impaired Individuals). MIAV complies with WCAG and Brazilian eMAG guidelines. The new method enables the assessment of some accessibility criteria in an automated way by AccessMonitor (FCT, 2012) and others based on the user experience and opinion of the visually-impaired individual. In order to validate the effectiveness of MIAV we asked blind students to identify accessibility and browsing issues and suggest improvements to IFFluminense's Portal, Q-Academico and Moodle.

\section{BACKGROUND}

In this section, we discuss state-of-the-art web application accessibility assessment, based on the study of standards and tools. Also, we describe some related works identified in literature. Granatto; Pallaro and Bim (2016) performed a systematic review of works published in the Brazilian Symposium on Human Factors in Computational Systems (IHC) between 1998 and 2015. They identified papers focusing on Digital Accessibility, $52 \%$ of which are related to web domains and $25 \%$ to visual impairment. Accessibility is an important topic that provides many research opportunities (Granatto, Pallaro and Bim, 2016). We conducted an ad hoc literature review and an international standards analysis to identify related works and accessibility criteria. The results show that accessibility assessment is generally carried out through tools, user experience and opinion or checking standards compliance.

From the accessibility standards perspective, WCAG principles are perceivable, operable, understandable and robust. These principles relate to 12 guidelines which contain one or more success criteria, totaling around 60 criteria. Each criterion is assessed against three levels of compliance. Level A is a basic level and does not ensure the accessibility of a web application because each of its pages must meet a success criteria subset. Level AA is an intermediate level that ensures accessibility for most users, since web pages must meet all A and AA success criteria. Level AAA is the highest level and aims to ensure accessibility, since web pages must meet all A, AA, and AAA success criteria. Brazilian eMAG is a tailored version of the WCAG guidelines for accessibility assessment of Brazilian government web applications. It contains sections on markup, behavior, content/information, presentation/design, multimedia and form. These sections list 45 accessibility recommendations.

Considering the number of criteria and web pages to be evaluated in a web application, tools such as AccessMonitor (FCT, 2012) can facilitate accessibility assessment by providing quick insights. W3C lists 122 tools consisting of software or online services that help to determine if web content meets accessibility guidelines. This list includes AccessMonitor with a dynamic logo that summarizes results based on samplings (W3C, 2016). An automatic evaluation method consists of algorithms that search the code of each page and highlight all nonconformities against the standards. However, these tools cannot properly evaluate some criteria. For instance, if the Alt attribute describes an image incorrectly the tool approves it. This case requires human assessment. Visually-impaired individuals could identify this problem, since they consider the context in which an image appears. In addition, evaluation methods that take into account user opinion and experience guarantee language clarity and opportunities to suggest improvements to the evaluated applications.

Visually-impaired users assessed WhatsApp's accessibility and identified several issues. Silva, Ferreira and Ramos (2016) related such issues with WCAG 2.0 success criteria and then reported problems regarding the perception, operation and understanding, except for the robust principle. Another study allowed visually-impaired people to evaluate UOL and Terra chat rooms in order to analyze user interactions (Ferreira, Silveira and Lima (2010). Melo and Baranauskas (2006) presented the Inclusive Participatory User Interface Evaluation (IPE) method. This technique supported the evaluation of the "Todos Nós" portal with the participation of users in an inclusive environment. Finally, Lima et al. (2018) adapted a protocol approach that focused on products and systems for the visually-impaired. This experiment evaluated the usability of the features of three accessibility aids: a Braille keyboard, DOSVOX and JAWS. The last two are screen readers 
having voice synthesizers. Thirty individuals participated in activities of entertainment, learning and social inclusion to demonstrate the suitability of specific accessibility features (LIMA et al., 2018).

About Moodle, Magalhães et al. (2010) reported usability issues. Also, Franciscato et al. (2008) carried out the suitability and usability evaluation of three virtual learning environments: Moodle, TelEduc and Tidia-Ae. Moodle ranked higher in the analysis of general data and availability of content in a hierarchical way. Neither of the former papers specifically refers to accessibility assessments by visually-impaired users.

\section{MATERIALS AND METHOD}

In this section, we describe tasks and tools supporting accessibility assessment using MIAV. MIAV aims to assess web pages' accessibility based on the experience and opinion of the visually impaired users when carrying out their activities. Also, we adopted the AccessMonitor (FCT, 2012) tool to test some WCAG 2.0 success criteria and e-Mag recommendations in an automated way. Thus, MIAV involved three stages: the planning, trial and execution stages including data collection and analysis, detailed in Figure 1.

\section{Planning}

1.1 Identifying user profiles and main activities they perform using the web application.

1.2 Stating relationships between accessibility criteria and main activities.

1.3 Developing data collection tools (WICF, evaluation guide and questionnaire).

1.4 Installing and setting tools (NVDA and Moodle).

\section{Trial}

2.1 Asking students to assess web application accessibility using tools.

2.2 Improving evaluationguide and questionnaire.

\section{Execution}

3.1 Recruiting participants.

3.2 Asking participants to assess web application accessibility using tools.

3.3 Running AccessMonitor tool.

3.4 Calculating accessibility indicators of web application.

3.5 Proposing web applications improvements.

Figure 1. MIAV's overview

During the planning phase, first we screened the visually-impaired user profiles and the main activities they perform using web applications. This screening consisted of a semi-structured interview with NAPNEE's coordinator to identify visually-impaired students' profiles and needs. Second, we assigned WCAG and eMAG criteria to the main activities. In addition, we decided which accessibility criteria would be evaluated using tools or user experience and opinion (questions Q1 to Q14), as in Table 1. Due to paper length limitations, more details on the numbers in Table 1 and WCAG success criteria tests by Access Monitor are available in FCT (2012), W3C (2016) and Brasil (2014). Third, based on the user profiles and the main activities, we developed data collection forms and tools including the written informed consent form (WICF), an evaluation guide and a questionnaire. Questions are in Table 1 plus two open questions to evaluate the screen reader used during accessibility assessment that is NVDA (NV ACCESS, 2017) and questionnaire itself. The evaluation guide lists and details the tasks that participants had to accomplish in the accessibility assessment. On IFFluminense's Portal, participants were asked to choose the news that drew their interests. After reading the news, they were asked to return to the main page and inform news' content. On Q-Academico, participants were asked to choose and inform the name of a course to obtain their attendance rate in percentage and save their enrollment voucher for the current term. 
Table 1. eMAG and WCAG criteria evaluation techniques

\begin{tabular}{|c|c|c|c|}
\hline \multicolumn{2}{|c|}{ eMag } & WCAG & Techniques \\
\hline \multirow[t]{9}{*}{ Markup } & 1.1 & $4.1 .1,4.1 .2$ & AccessMonitor \\
\hline & 1.2 & 1.3 .1 & AccessMonitor \\
\hline & 1.3 & $1.3 .1,2.4 .10$ & AccessMonitor \\
\hline & 1.4 & $1.3 .2,2.4 .3$ & AccessMonitor \\
\hline & 1.5 & 2.4 .1 & AccessMonitor \\
\hline & 1.6 & 1.3 .1 & AccessMonitor \\
\hline & 1.7 & 1.3 .1 & AccessMonitor \\
\hline & 1.8 & 3.2 .3 & Not evaluated \\
\hline & 1.9 & 3.2 .5 & AccessMonitor \\
\hline \multirow[t]{7}{*}{ Behavior } & 2.1 & $2.1 .1,2.1 .2$ & AccessMonitor \\
\hline & 2.2 & $2.1 .1,2.1 .2$ & AccessMonitor \\
\hline & 2.3 & 3.2 .5 & AccessMonitor \\
\hline & 2.4 & 3.2 .5 & AccessMonitor \\
\hline & 2.5 & 2.2 .1 & AccessMonitor \\
\hline & 2.6 & 2.3.1 & Not evaluated \\
\hline & 2.7 & 2.2 .2 & AccessMonitor \\
\hline Content/ & 3.1 & 3.1 .1 & AccessMonitor \\
\hline \multirow[t]{11}{*}{ information } & 3.2 & 3.1 .2 & $\begin{array}{l}\text { Q1. Did you notice when there was a language change in the web } \\
\text { application's content? }\end{array}$ \\
\hline & 3.3 & 2.4.2 & AccessMonitor \\
\hline & 3.4 & 2.4 .8 & Q2. Did the web application report your location on site? \\
\hline & 3.5 & 2.4.4, 2.4.9 & Q3. Did the web application describe links clearly and succinctly? \\
\hline & 3.6 & 1.1 .1 & AccessMonitor \\
\hline & 3.7 & 1.1.1 & AccessMonitor \\
\hline & 3.8 & & $\begin{array}{l}\text { Q4. Did the web application make content available in accessible } \\
\text { formats? }\end{array}$ \\
\hline & 3.9 & 1.3 .1 & AccessMonitor \\
\hline & 3.10 & 1.3 .1 & AccessMonitor \\
\hline & 3.11 & 3.1 .5 & $\begin{array}{l}\text { Q5. Did the web application allow reading and understanding the } \\
\text { information? }\end{array}$ \\
\hline & 3.12 & 3.1.3, 3.1.4 & $\begin{array}{l}\text { Q6. Did the web application provide an explanation for the acronyms, } \\
\text { abbreviations and unusual words? }\end{array}$ \\
\hline Presentation/ & 4.1 & 1.4 .3 & AccessMonitor \\
\hline \multirow[t]{3}{*}{ design } & 4.2 & $1.3 .3,1.4 .1$ & Not evaluated \\
\hline & 4.3 & 1.4 .4 & AccessMonitor \\
\hline & 4.4 & 2.4.7 & $\begin{array}{l}\text { Q7. Did the web application evidence elements with focus, that is, the } \\
\text { selected element was read? }\end{array}$ \\
\hline \multirow[t]{5}{*}{ Multimedia } & 5.1 & $1.2 .1,1.2 .2,1.2 .6,1.2 .8$ & AccessMonitor \\
\hline & 5.2 & $1.2 .1,1.2 .2,1.2 .6$ & AccessMonitor \\
\hline & 5.3 & $1.2 .3,1.2 .5,1.2 .7$ & Q8. Did the web application offer audio description for videos? \\
\hline & 5.4 & 1.4 .2 & Q9. Did the web application provide audio control for sound? \\
\hline & 5.5 & 2.2.2 & $\begin{array}{l}\text { Q10. Did the web application allow you to pause, stop or hide the } \\
\text { video, slideshow or animation available on the homepage? }\end{array}$ \\
\hline \multirow[t]{8}{*}{ Form } & 6.1 & 1.1 .1 & Q11.Did the web application provide a text alternative for buttons? \\
\hline & 6.2 & 1.3 .1 & AccessMonitor \\
\hline & 6.3 & 2.4 .3 & Q12.Did the web application establish a logical browsing order? \\
\hline & 6.4 & 3.3.2 & AccessMonitor \\
\hline & 6.5 & 3.3 .2 & $\begin{array}{l}\text { Q13. Did the web application confirm the login form information was } \\
\text { duly submitted? }\end{array}$ \\
\hline & 6.6 & 3.3.1 & $\begin{array}{l}\text { Q14. Did the web application identify and describe the data entry } \\
\text { errors? }\end{array}$ \\
\hline & 6.7 & 1.3 .1 & AccessMonitor \\
\hline & 6.8 & 1.1 .1 & AccessMonitor \\
\hline
\end{tabular}

Whenever needed, we set up the tools to carry out the accessibility assessment. In particular, we installed NVDA and we created a course with three activities in Moodle provided by IFFluminense, to allow students to make the accessibility assessment. In activity 1 , we verified if the visually-impaired students were able to 
access Moodle's content in PDF format, which is often made available by teachers. Activity 2 has an external link to evaluate the HTML content. In activity 3, we investigated if students were able to assess Moodle's and its educational videos' accessibility, observing the audio shift between NVDA and video. Students performed tasks on IFFluminense's Portal and Q-Academico as they were on the assessment date, using their own access credentials.

At the trial stage, after the "Web Accessibility: A Practical Approach" short course was given in July 2018, we asked 7 students to assess a web page's accessibility. As only one participant was visually impaired, we instructed others to turn off their computer monitor and put on their headphones to mimic a blind user experience. We advised them to complete the evaluation guide activities and questionnaire, available in TXT format, using the NVDA screen reader. Also students received a printed list of basic NVDA and computer commands. Based on the pilot-test results, we improved the data collection tools as follows: (i) replacing the multiple-choice questions for open questions because using the screen reader confused participants to choose their answers; (ii) giving easier-to-understand instructions in the evaluation guide.

The data collection and analysis stage begins with the recruitment of the participants. In this research, participants were selected by convenience, specifically partially- or fully-blind IFFluminense students. We sent an invitation with the WICF for five visually-impaired students assisted by NAPNEE, three of whom accepted to assess IFFluminense's Portal's, Q-Academico's and Moodle's accessibility. They completed the evaluation guide and the questionnaire. Next, we ran AccessMonitor on the same pages they evaluated, to evaluate other criteria. AccessMonitor showed the accessibility index and level. We also calculated the average accessibility index for IFFluminense's Portal's, Q-Academico's and Moodle's evaluated pages. Finally, based on the results, we suggest improvements on the evaluated web applications.

\section{RESULTS AND DISCUSSIONS}

\subsection{Participants Characterization}

Three visually-impaired students individually assessed IFFluminense's Portal's, Q-Academico's and Moodle's accessibility in August 2018. It took them two hours to complete proposed activities in the evaluation guide and to answer the questionnaire. We named participants P1, P2 and P3. All participants are female, aged between 23 and 26. P1 and P2 were IT professionals and Geography and Information System students respectively. P3 was a computer technician student. They reported being familiar with NVDA and technology-skilled when performing routine and academic activities. They use the smartphone for leisure and communication. They use both the computer and the smartphone to check their academic achievement in Q-Academico. One participant reported using it daily. They read news on IFFluminense's Portal at the computer; two participants reported doing it weekly. Although no participant had used Moodle before, we asked them to assess its accessibility because they might use it in the future.

\subsection{Accessibility Level and Related Issues}

Table 2 shows the results for each accessibility assessment question in Table 1. Blank cells indicate the question is not applicable to that web application. Participants were comfortable to answer some questions in detail, not following the evaluation guide's directions to type "Y" for Yes, "N" for No, "NA" for "Not Applicable" or "IDK" for "I do not know". In such cases, their answers were adjusted and highlighted (*).

As for IFFluminense's Portal, all participants reported that their location on the web page was not informed (Q2). Two participants stated that no explanation for acronyms, abbreviations or unusual words was provided. P3 reported that she did not know the answer (Q6). For Q10, two participants indicated that it did not apply and P1 gave a negative answer. As for questions Q11 and Q12, two participants answered "Y". However, all participants confirmed that links were described in a clear, direct way (Q3); web content reading and understanding was guaranteed (Q5). On Q-Academico, all participants answered "Y" for Q3, Q7, Q11, Q12 and Q13. Only P3 recalled that the enrollment voucher had not been made available in an accessible format. This document is presented as an image without any text description. As for Moodle, all participants were able to carry out the three activities. They all agreed that Moodle's links were presented in a clear, direct way (Q3). Content was in an accessible format (Q4); web content reading and understanding was guaranteed (Q5); and 
the selected elements were read and highlighted (Q7 and Q13). However, P1 said that Moodle failed to identify data entry errors (Q14) and on which web page they were (Q2). They all reported that Moodle did not offer audio description for the available videos $(\mathrm{Q} 8)$. These results demonstrate that none of the evaluated web pages met the accessibility criteria when evaluated by visually-impaired users.

Table 2. Accessibility assessment results

\begin{tabular}{|c|c|c|c|c|c|c|c|c|c|}
\hline \multirow[t]{2}{*}{ Questions } & \multicolumn{3}{|c|}{ IFFluminense's Portal } & \multicolumn{3}{|c|}{ Q-Academico } & \multicolumn{3}{|c|}{ Moodle } \\
\hline & P1 & $\mathrm{P} 2$ & P3 & P1 & $\mathrm{P} 2$ & P3 & $\mathrm{P} 1$ & $\mathrm{P} 2$ & P3 \\
\hline Q1 & & & & & & & NA* & $\mathrm{N}$ & $\mathrm{N}$ \\
\hline Q2 & $\mathrm{N}$ & $\mathrm{N}$ & $\mathrm{N}$ & $\mathrm{N}$ & Y & $\mathrm{Y}$ & $\mathrm{N}$ & Y & $\mathrm{Y}$ \\
\hline Q3 & $\mathrm{Y}$ & Y & $\mathrm{Y}^{*}$ & Y & Y & Y & Y & Y & Y \\
\hline Q4 & & & & & & & Y & Y & $\mathrm{Y}$ \\
\hline Q5 & $\mathrm{Y}$ & $\mathrm{Y}$ & Y & $\mathrm{Y}$ & $\mathrm{Y}$ & $\mathrm{N}$ & $\mathrm{Y}$ & $\mathrm{Y}$ & $\mathrm{Y}$ \\
\hline Q6 & $\mathrm{N}$ & $\mathrm{N}$ & IDK* & $\mathrm{NA}^{*}$ & $\mathrm{~N}$ & $\mathrm{Y}^{*}$ & NA* & $\mathrm{N}$ & $\mathrm{Y}$ \\
\hline Q7 & $\mathrm{Y}$ & $\mathrm{N}$ & $\mathrm{Y}$ & $\mathrm{Y}$ & $\mathrm{Y}$ & $\mathrm{Y}$ & $\mathrm{Y}$ & $\mathrm{Y}$ & $\mathrm{Y}$ \\
\hline Q8 & & & & & & & $\mathrm{N}$ & $\mathrm{N}$ & $\mathrm{N}$ \\
\hline Q9 & & & & & & & $\mathrm{Y}$ & $\mathrm{N}$ & $\mathrm{Y}$ \\
\hline Q10 & NA* & $\mathrm{N}^{*}$ & NA* & & & & & & \\
\hline Q11 & $\mathrm{Y}$ & $\mathrm{Y}$ & $\mathrm{N}$ & $\mathrm{Y}$ & $\mathrm{Y}$ & $\mathrm{Y}$ & & & \\
\hline Q12 & Y & Y & IDK* & $\mathrm{Y}$ & Y & $\mathrm{Y}$ & & & \\
\hline Q13 & & & & $\mathrm{Y}$ & Y & $\mathrm{Y}$ & $\mathrm{Y}$ & Y & Y \\
\hline Q14 & & & & $\mathrm{N}$ & $\mathrm{Y}$ & $\mathrm{Y}$ & $\mathrm{N}$ & $\mathrm{Y}$ & Y \\
\hline
\end{tabular}

Other accessibility issues were observed when using the evaluation guide. When participants accessed a link leading to a wrong page, they were not able to return to the previous page by pressing the "Backspace" key. They all had to enter the URL to access the home page again. Q-Academico's login page does not differentiate the fields for login and password. In this case, NVDA informed only "editing", which troubled access by blind users. Similarly, the participants who did not copy and paste the password "Aluno12." from the evaluation guide on Moodle were not able to access it. That happened because NVDA is not case sensitive for letter "A" and does not read the period "." in the password, although capital letters and special characters are required for passwords on Moodle. Also, Moodle request confirming completion of each task. But because NVDA does not read the "Once submitted, you will not be able to change the answers for this attempt" message in the pop-up box, it was not heard by participants. These problems are difficult to detect when blind users do not participate in the accessibility assessment.

When asked how these web applications could be improved, $\mathrm{P} 3$ reported that a lot of information is repeated on IFFluminense's Portal and on Moodle's pages. P2 and P3 suggested that web pages' content be provided in a readable format for screen readers. Also, P1 suggested more shortcuts to facilitate information access. However, no participant suggested improvements for NVDA. As for the evaluation guide, all participants found it easy to follow the directions and to understand the questions. Because the guide aimed to evaluate three software products in a row, more questions and directions were given, which caused participants to rate it as long and tiresome. We hope this issue is resolved by using MIAV to evaluate only one web application at a time.

In order to complete the accessibility evaluation, AccessMonitor automatically tested the remaining accessibility criteria in Table 1 . AccessMonitor counts nonconformities and calculates the accessibility index for each evaluated web page. Refer to FCT (2012) for more details. Based on these data two indicators for each web application were generated: (i) the average accessibility index and (ii) percentage of nonconformities corresponding to each accessibility level. The average index for the four pages from Moodle was 6.8. The five assessed pages from IFFluminense's Portal resulted in an average index of 5.6. The three assessed pages from Q-Academico were assigned an average index of 4.3. The best result achieved by Moodle matches that reported by Franciscato et al. (2008). That signals a usability and accessibility concern by Moodle's developers.

Table 3 shows the percentage of nonconformities. Blank cells indicate that the assessed web application passed the accessibility test. Items such "markup of links, menus and text links" and "presentation/obsolete elements and attributes" are the most significant, since they impact all evaluated applications. Conversely, issues related to metadata, information contrast, data tables and layout tables were not identified. Yet all assessed pages failed to achieve the A accessibility level provided by AccessMonitor because web applications had at least one nonconformity for levels A, AA or AAA. 
Table 3. Percentage of nonconformities by accessibility level (\%)

\begin{tabular}{|c|c|c|c|c|c|c|c|c|c|c|}
\hline \multirow[t]{2}{*}{ WCAG 2.0} & \multirow[t]{2}{*}{ AccessMonitor tests } & \multicolumn{3}{|c|}{$\begin{array}{l}\text { IFFluminense's } \\
\text { Portal }\end{array}$} & \multicolumn{3}{|c|}{ Q-Academico } & \multicolumn{3}{|c|}{ Moodle } \\
\hline & & A & AA & AAA & A & AA & AAA & A & AA & AAA \\
\hline 1.1 .1 & Image alternative text & 7.0 & & & 6.2 & & & 6.2 & & \\
\hline 1.1 .1 & Markup of Image maps & 6.2 & & & & & & & & \\
\hline 2.4.1, 4.1.2 & Insertion of Multimedia & 5.9 & & & & & & & & \\
\hline $1.3 .1,2.4 .10$ & Markup of header & & & & 5.9 & & & & & 5.6 \\
\hline $\begin{array}{l}2.4 .5,2.4 .4,2.4 .9, \\
4.1 .2\end{array}$ & $\begin{array}{l}\text { Markup of links, menus and text } \\
\text { links }\end{array}$ & 5.9 & & 25.0 & 5.9 & 100.0 & & & & 25.0 \\
\hline 2.4 .1 & Links to skip information blocks & 12.5 & & & 25.0 & & & & & \\
\hline $\begin{array}{l}\text { 1.1.1, 1.3.1, 3.2.2, } \\
3.3 .2,4.1 .2\end{array}$ & $\begin{array}{l}\text { Markup of } \\
\text { forms }\end{array}$ & 2.2 & & & 4.3 & & & & & \\
\hline 4.1 .1 & Standards W3C: (X) HTML + CSS & 12.5 & & & 12.5 & & & 12.5 & & \\
\hline $\begin{array}{l}\text { 1.3.1, 1.4.1, 1.4.4, } \\
1.4 .5,1.4 .9\end{array}$ & $\begin{array}{l}\text { Presentation/obsolete elements and } \\
\text { attributes }\end{array}$ & 4.3 & & & 5.8 & 3.6 & & 5.9 & 3.6 & \\
\hline 1.4 .4 & Use of absolute units & & 20.0 & & & 40.0 & & & & \\
\hline $2.4 .2,2.4 .5,2.4 .8$ & Metadata & & & & & & & & & \\
\hline 3.1.1 & Markup of page primary language & & & & 25.0 & & & 25.0 & & \\
\hline 1.4.3, 1.4.6, 1.4.8 & Information contrast & & & & & & & & & \\
\hline 1.4 .8 & Text formatting & & & 25.0 & & & 16.7 & & & \\
\hline 1.3.1 & Data tables & & & & & & & & & \\
\hline 1.3.2 & Layout tables & & & & & & & & & \\
\hline $2.1 .1,2.1 .3$ & JavaScript use & & & & 20.0 & & & & & \\
\hline
\end{tabular}

From AccessMonitor results and analysis of user experience and opinion, we suggested improvements for the web applications. The enrollment voucher provided by Q-Academico should be compatible with screen readers; the first link on Q-Academico and IFFluminense's Portal should lead users back to the homepage, and provide a shortcut key on the keyboard associated to that link; IFFluminense's Portal and Moodle should have shortcut commands to allow easy access to the main content. Finally, non-textual content should have an equivalent textual description in all web applications.

\section{CONCLUSION}

This research contributed to MIAV's development, so that visually-impaired individuals identify accessibility fails, according to national and international standards. MIAV proved to be effective in its implementation to assess web application's accessibility and identify significant improvements for IFFluminense's Portal, Q-Academico and Moodle. MIAV strongly contributed to identify major accessibility problems in the assessed web pages. Developers of these software products can solve their accessibility shortcomings to provide visually-impaired students with fully accessible content. In addition, the evaluation guide was considered understandable and easy-to-use by the visually-impaired.

By comparing MIAV against related works, we feature that MIAV combines two techniques for accessibility assessment: an automated one and one based on experience and opinion of visually-impaired users. Franciscato et al. (2008) and Magalhães et al. (2010) evaluated Moodle's usability. However, we suggest MIAV to specifically assess accessibility. Moreover, IFFluminense's Portal's and Q-Academico's accessibility were assessed, which is unprecedented in the literature.

Among this study's limitations, we highlight that in the pilot test most of the participants did not have any visual impairment or experience with NVDA. Due to the limited number of available visually- impaired students, we asked sighted students to experience total blindness by turning off their computer's monitor. This pilot test allowed us to enhance the evaluation guide and questionnaire, and raise participants' awareness about how important web accessibility is, which was the purpose of the short course.

Despite the number of blind participants being very small, Nielsen and Landauer (1993) argued that a single evaluator can identify one-third of usability problems, but three evaluators are enough to map out $70 \%$ of them. Indeed, in MIAV's implementation participants pointed out some relevant accessibility problems. 
Only a fraction of the pages of each web application was assessed because the web pages are dynamic, which requires that MIAV be applied periodically to assess their current accessibility level. Finally, MIAV proved to be effective in identifying relevant improvements, whose impact can be the object of future study.

\section{REFERENCES}

Brasil, 1996. LDB Law of Directives and Bases of National Education, Brazil. Accessed 07-07-2017 at <http://www.planalto.gov.br/ccivil_03/LEIS/L9394.htm>.

Brasil, 2014. eMAG - Accessibility Model in Electronic Government, Brazil. Accessed 07-07-2017 at $<$ http://emag.governoeletronico.gov.br/>.

Brasil, 2015. Brazilian Law on the Inclusion of Persons with Disabilities (Statute of Persons with Disabilities), Brazil. Accessed 07-07-2017 at < http://www.planalto.gov.br/ccivil_03/_Ato2015-2018/2015/Lei/L13146.htm>.

Brasil, 2017. Portal IFF - Federal Institute of Education, Science and Technology Fluminense, Brazil. Accessed 07-07-2017 at <http://portal1.iff.edu.br/>.

FCT, Foundation for Science and Technology, 2013. AccessMonitor. ACCESS Unit of FCT, I.P. Portugal. Accessed 08-06-2018 at <http://www.acessibilidade.gov.pt/accessmonitor/>.

Ferreira, S., Silveira, D., Lima, C., 2010. Accessibility assessment of communication systems with the participation of people with total visual impairment. Proceedings of National Meeting of Postgraduate Programs in Administration. Brasília. Brazil. pp. 1-10.

Franciscato, F. et al., 2008. Evaluation of the Virtual Learning Environments Moodle, TelEduc and Tidia-Ae: a comparative study. In RENOTE, Vol. 6, No. 1.

Granatto, C., Pallaro, M. A., Bim, S., 2016. Digital Accessibility: Systematic Review of Papers from the Brazilian Symposium on Human Factors in Computer Systems. Proceedings of the 15th Brazilian Symposium on Human Factors in Computing Systems. ACM. pp. 1-10.

IBGE, Brazilian Institute of Geography and Statistics, 2013. Perception of health status, lifestyles and chronic diseases Brazil, Major Regions and Federation Units. Accessed 07-07-2017 at <http://www.ibge.gov.br/home/estatistica/populacao/pns/2013/default.shtm>.

ISO/IEC, 2011. ISO/IEC 25010:2011. Systems and software engineering — Systems and software Quality Requirements and Evaluation (SQuaRE) - System and software quality models.

ISO/IEC, 2012. ISO/IEC 40500:2012. Information technology - W3C Web Content Accessibility Guidelines (WCAG) 2.0.

Lima, A. et al., 2018. Evaluation system accessibility using an experimental protocol based on usability. Proceedings 12th International Conference Interfaces and Human Computer Interaction. Madrid, Spain, pp. 85-92.

Magalhães, E. et al., 2010. Impact of Usability in Distance Education: A Case Study in the Moodle IFAM. Proceedings of the Brazilian Symposium on Human Factors in Computer Systems. Manaus. Brazil.

Melo A. M., Baranauskas M., 2006. An Inclusive Option for Cooperative Assessment of User Interfaces. Proceedings of the XXVI SBC Congress. Campinas, Brazil. p. 447-461.

Moodle. Moodle PTCE - Campus Campos Centro. Published 07-07-2017 at <http://ensino.centro.iff.edu.br/moodle/>.

NV Access. About NVDA. Accessed 07-07-2017 at <https://www.nvaccess.org/>

Qualidata. Welcome to Q-Academico Web. Accessed 07-07-2017 at <https://academico.iff.edu.br/>.

Nielsen, J., Landauer, T., 1993. A mathematical model of the finding of usability problems. Proceedings of the INTERACT'93 and CHI'93 conference on Human factors in computing systems. ACM. Amsterdam, The Netherlands, pp. 206-213

Sartoretto, M., Bersch, R., 2017. Assistive Technology and Education. Accessed 07-07-2017 at <http://www.assistiva.com.br/tassistiva.html>.

W3C, World Wide Web Consortium, 2008. Web content accessibility guidelines (WCAG), version 2.0. Accessed 07-07-2017 at <https://www.w3.org/Translations/WCAG20-pt-PT/>.

W3C, World Wide Web Consortium, 2016. Web Accessibility Evaluation Tools List. Updated March 2016 at <https://www.w3.org/WAI/ER/tools/>. 